\title{
ESTADO NUTRICIONAL DE MARACUJAZEIRO-AMARELO IRRIGADO COM ÁGUA SALINA E ADUBAÇÃO ORGANOMINERAL ${ }^{1}$
}

\author{
JOSÉ ADEILSON MEDEIROS DO NASCIMENTO², LOURIVAL FERREIRA CAVALCANTE ${ }^{3}$, \\ STÊNIO ANDREY GUEDES DANTAS ${ }^{4}$, SHERLY APARECIDA DA SILVA ${ }^{4}$
}

RESUMO - A nutrição mineral é essencial para elevar a produtividade e melhorar a qualidade dos frutos de maracujazeiro-amarelo. O objetivo deste trabalho foi avaliar o efeito da aplicação de biofertilizante comum sobre os teores de macronutrientes de plantas de maracujazeiro-amarelo irrigadas com água salina em solo sem e com adubação mineral. Os tratamentos foram distribuídos em blocos ao acaso, com três repetições e quatro plantas por parcela. Foi usado o arranjo fatorial $4 \times 2$, relativo aos níveis de biofertilizante bovino fermentado, diluído em água, a 0,0; 33,3; 66,6 e 100\%, em solo sem e com adubação mineral. A irrigação foi realizada pelo método de aplicação localizada por gotejamento com água salina, oriunda de poço amazonas, com condutividade elétrica média de $4 \mathrm{dS} \mathrm{m}^{-1}$. A aplicação de biofertilizante ao solo, exceto para cálcio, supriu adequadamente as plantas de maracujazeiro- amarelo em macronutrientes, mas com superioridade de valores nos tratamentos com adubação mineral.

Termos para indexação: Passiflora edulis f. flavicarpa Deg., nutrição mineral, insumo orgânico.

\section{NUTRITIONAL STATUS OF YELLOW PASSION FRUIT UNDER SALINE WATER IRRIGATION AND ORGANIC-MINERAL FERTILIZING}

\begin{abstract}
Plant nutrition is essential to improve productivity and increase fruit quality of the passion fruit. This experiment aimed to evaluate the passion fruit nutrition under different planting densities and fertilization. A complete randomized block design was adopted with three repetitions and four plants per parcel, using factorial arrangement $4 \times 2$, referring to bovine in soil with and without NPK. The irrigation was performed daily, with saline water (electrical conductivity $=4,0 \mathrm{dS} \mathrm{m}^{-1}$ ), using drip irrigation. The application of liquid bovine fertilizer, except for calcium, supplied properly the passion fruit plants in macronutrientes, showing higher results in the treatments with mineral fertilizer.
\end{abstract}

Index terms: Passiflora edulis f. flavicarpa Deg., mineral nutrition, organic input

\section{INTRODUÇÃO}

O Brasil ocupa, desde a década de 90, a posição de maior produtor e exportador mundial de frutos de maracujazeiro-amarelo (Passiflora edulis f. flavicarpa Deg.), e mantém a posição devido à grande quantidade de terras agricultáveis e condições edafoclimáticas favoráveis à cultura. Atualmente, são explorados em torno de 50 mil hectares por ano com a cultura, que apresenta alto potencial de cultivo em quase todos os estados brasileiros (IBGE, 2010). No entanto, o rendimento médio da produção nacional está em torno de $15 \mathrm{t} \mathrm{ha}^{-1}$, um va- lor considerado muito baixo levando em consideração que a cultura apresenta potencial para produzir até $42 \mathrm{t} \mathrm{ha}^{-1}$ (EMBRAPA, 2010).

Estudos direcionados à adubação adequada e nutrição mineral das plantas é um dos fatores essenciais para garantir o aumento de produtividade e a expansão da passicultura no Brasil. A nutrição mineral é um dos fatores que mais contribuem para o aumento da produtividade e a qualidade dos frutos, principalmente em solos de regiões tropicais, geralmente de baixa fertilidade. As informações a respeito de teores adequados de nutrientes na matéria seca de plantas de maracujazeiro-amarelo apresentam

\footnotetext{
${ }^{1}$ Trabalho Sinfruit 070 - Simpósio Internacional de Fruticultura - Avanços na Fruticultura (17 a 21 Outubro) ${ }^{2}$ PPGA/CCA/UFPB, Vila acadêmica, CEP 58397-000, Areia-PB. Fone: (83) 3362-2300. Fax: (83) 3362-2359. E-mail (s): adeilsonagro@bol.com.br.; tagdantas@yahoo.com.br.

${ }^{3}$ DSER/CCA/UFPB, Vila Acadêmica, CEP 58397-000, Areia-PB. Fone: (83) 3362-2300. Fax: (83) 3362-2359.

E-mail: lofeca@cca.ufpb.br.

${ }^{4}$ Estudante de graduação, Vila acadêmica, CEP 58397-000, Areia, PB. Fone: (83) 3362-2300. Fax: (83) 3362-2359.

E-mail: sherly.agro@hotmail.com, stenioandrey@hotmail.com.
} 
divergências para alguns nutrientes, o que ocorre em função da condição e da metodologia sob a qual foram feitas as aferições (MALAVOLTA et al.,1997; OLIVEIRA, 2002). Em função dessas variações, Resende et al. (2008) recomendam que o produtor procure estabelecer valores de referência para as condições específicas de cultivo de sua lavoura.

A utilização de insumos sintéticos eleva significativamente a produtividade do maracujazeiro, principalmente em solos de baixa fertilidade, mas, por outro lado, é um dos fatores que mais oneram os custos de produção da cultura nos sistemas convencionais de manejo (HAFLE et al., 2010). No Nordeste brasileiro, responsável por grande parte da produção nacional, a cultura é explorada em pequenas áreas, geralmente com mão de obra familiar de escassos recursos financeiros, de modo que alternativas para reduzir o custo de produção são essenciais para torná-la uma cultura viável, como inclusive comentam Pires et al. (2008). A escassez de água de boa qualidade para irrigação e a irregularidade pluviométrica nas áreas semiáridas produtoras de maracujá-amarelo também dificultam a utilização de fertilizantes sintéticos pelos agricultores. Além disso, o emprego de tais insumos em cultivos irrigados com água salina, que são frequentes nessa região, requer atenção especial devido aos altos índices salinos apresentados, principalmente pelos adubos nitrogenados e potássicos, que podem potencializar o efeito negativo da salinidade da água sobre a cultura (DIAS et al., 2007; FREIRE et al., 2010).

O desequilíbrio nutricional das plantas é um dos principais problemas provocados pela salinidade da água de irrigação, haja vista que o teor de sais e de sódio em excesso na água pode inibir a absorção de nutrientes essenciais, como potássio, cálcio e magnésio, e provocar desbalanço na relação $\mathrm{K}^{+} / \mathrm{Na}^{+}$, responsável pelo ajuste osmótico celular (YOSHIDA, 2002). Por outro lado, os sais contidos na água reduzem o potencial osmótico da solução do solo, reduzindo a absorção de água e os nutrientes essenciais às plantas e aumentando a absorção de elementos como cloro e sódio que, em excesso nos tecidos vegetais, provocam toxidez (MUNNS; TESTER, 2008).

Para reduzir os custos com adubação mineral e mitigar os efeitos negativos da salinidade da água no maracujazeiro, uma alternativa pode ser a substituição parcial e até total dos fertilizantes de custos elevados, por insumos orgânicos, como os biofertilizantes obtidos a partir de esterco fresco de bovino. Esses insumos, além de terem preços mais acessíveis, influenciam positivamente com a maté- ria orgânica e substâncias húmicas às propriedades químicas, físicas e biológicas do solo. Apesar de não substituir totalmente os fertilizantes na nutrição de maracujazeiro-amarelo, Rodrigues et al. (2009) verificaram que o biofertilizante apresenta resultados promissores sobre a produção da cultura. Por outro lado, o insumo pode, também, exercer efeitos positivos na redução do potencial osmótico no interior das plantas, em relação à solução do solo, possibilitando a absorção de água e nutrientes sob condições de estresse salino (BAALOUSHA et al., 2006).

Alguns trabalhos já registram efeitos benéficos da aplicação de biofertilizantes fermentados sobre a nutrição de plantas de maracujazeiro irrigado com água não salina (DINIZ, 2009). No entanto, mesmo com o fato de regiões de produção expressiva no Nordeste apresentarem grande parte das suas fontes hídricas comprometidas pelo excesso de sais, ainda não são frequentes na literatura científica registros dos efeitos desses benefícios dos biofertilizante sobre a composição nutricional de maracujazeiro-amarelo irrigado com água salina. Dessa forma, o objetivo do trabalho foi avaliar o efeito da aplicação de biofertilizante comum sobre os teores de macronutrientes em plantas de maracujazeiro-amarelo irrigadas com água salina em solo sem e com adubação mineral.

\section{MATERIAL E MÉTODOS}

O experimento foi conduzido, no período de outubro de 2008 a novembro de 2009 , no município de Jaçanã - RN, Platô da Serra de Cuité, onde o clima é classificado, conforme Koeppen, do tipo As', quente e seco. As chuvas concentram-se nos meses de março a julho. Os valores médios de pluviosidade no local, em 2008 e 2009, foram 863 e 1.100 $\mathrm{mm}$, respectivamente. $\mathrm{O}$ solo no local do experimento é classificado como LATOSSOLO VERMELHO-AMARELO eutrófico de textura francoarenosa e não salino $\left(0,75 \mathrm{dS} \mathrm{m}^{-1}\right)$. Antes da instalação do experimento, foi realizada uma caracterização da fertilidade do solo (profundidade de $0-40 \mathrm{~cm}$ ) e foram registrados os seguintes valores: $\mathrm{pH}=7,59 ; \mathrm{P}=$ $10 \mathrm{mg} \mathrm{dm}{ }^{-3} ; \mathrm{K}^{+}=110,11 \mathrm{mg} \mathrm{dm}{ }^{-3} ; \mathrm{Na}^{+}=0,20 \mathrm{cmol}$ $\mathrm{dm}^{-3} ; \mathrm{H}^{+}+\mathrm{Al}^{3+}=1,23 \mathrm{cmol}_{\mathrm{c}} \mathrm{dm}^{-3} ; \mathrm{Al}^{3+}=0,0 \mathrm{cmol}$ $\mathrm{dm}^{-3} ; \mathrm{Ca}^{2+}=2,40 \mathrm{cmol}_{\mathrm{c}} \mathrm{dm}^{-3} ; \mathrm{Mg}^{2+}=1,47 \mathrm{cmol}_{\mathrm{c}} \mathrm{dm}^{-3}$ e matéria orgânica $=8,01 \mathrm{~g} \mathrm{~kg}^{-1}$.

Os tratamentos foram distribuídos em blocos ao acaso, com três repetições e quatro plantas por parcela, adotando o arranjo fatorial $4 \times 2$, relativo a quatro níveis de biofertilizante bovino diluído em água, nas proporções de $0 ; 33,3 ; 66,6$ e 100\%, em 
solo sem e com adubação mineral NPK. O biofertilizante foi fornecido aplicando-se um volume de 6 L planta $^{-1}$ de cada nível, 30 dias antes, e cada 60 dias após o transplantio das mudas em campo, até o final do experimento. O biofertilizante foi produzido a partir da mistura de partes iguais de esterco bovino fresco de vacas em lactação e água não clorada e não salina, em recipiente hermeticamente fechado, durante 30 dias, em local sombreado sob fermentação anaeróbia. Durante o período do experimento, foram realizadas sete aplicações de biofertilizante e, em cada ocasião, uma amostra do insumo em cada diluição $(33,3 ; 66,6$ e 100\%) foi coletada para caracterização química como se fosse água para irrigação, e os valores médios estão apresentados na Tabela 1.

As mudas do maracujazeiro-amarelo foram formadas em bolsas de polietileno de $18 \mathrm{~cm}$ de altura e 13 de diâmetro, e foram transplantadas quando estavam com quatro ou cinco pares de folhas, o que equivale a uma altura de $30 \mathrm{~cm}$. O transplantio foi realizado no final de outubro, período com pouco ou quase nenhum registro de pluviosidade na região. As covas para o plantio foram abertas com dimensões de $40 \mathrm{~cm} \times 40 \mathrm{~cm} \times 40 \mathrm{~cm}$, no espaçamento $2,5 \mathrm{~m}$ entre linhas e $3 \mathrm{~m}$ entre plantas. As plantas foram conduzidas no sistema de espaldeira vertical, em haste única até o fio de arame, à altura de 2,20 m, e, em seguida, em dois ramos horizontais em sentidos opostos, ao longo do arame de sustentação. Juntamente com a primeira aplicação de biofertilizante, 30 dias antes do transplantio, foram acrescentados, em todas as covas, $10 \mathrm{~L}$ de esterco de bovino curtido, juntamente com 7,48 g de $\mathrm{P}_{2} \mathrm{O}_{5}$ na forma de superfosfato simples. $\mathrm{O}$ esterco bovino foi caracterizado quimicamente $\mathrm{e}$ apresentou os seguintes valores: $\mathrm{pH}=8,81 ; \mathrm{P}=1526$ $\mathrm{mg} \mathrm{dm}{ }^{-3} ; \mathrm{K}^{+}=3170 \mathrm{mg} \mathrm{dm}^{-3} ; \mathrm{Na}^{+}=10,13 \mathrm{cmol}_{\mathrm{c}} \mathrm{dm}^{-3}$; $\mathrm{H}^{+}+\mathrm{Al}^{3+}=1,65 \mathrm{cmol}_{\mathrm{c}} \mathrm{dm}^{-3} ; \mathrm{Al}^{3+}=0,0 \mathrm{cmol}_{\mathrm{c}} \mathrm{dm}^{-3} ; \mathrm{Ca}^{2+}=$ 7,$8 ; \mathrm{Mg}^{2+}=9,5$ e matéria orgânica $=192,4 \mathrm{~g} \mathrm{~kg}^{-1}$.

A adubação química, de cobertura, foi realizada com base nos teores de nutrientes apresentados no solo previamente e na exigência da cultura. Aos 30 dias após transplantio, nos tratamentos com adubação mineral, foram fornecidos $5 \mathrm{~g}$ de $\mathrm{N}$ e $5 \mathrm{~g}$ de $\mathrm{K}_{2} \mathrm{O}$, oriundos de ureia e $\mathrm{KCl}$, respectivamente, e $10 \mathrm{~g}$ de $\mathrm{N}$ aos 60 dias após o transplantio das mudas. A partir dos 90 dias após transplantio, mensalmente, foram fornecidos $20 \mathrm{~g}$ de $\mathrm{N}$, a cada 30 dias, até o final do experimento. No período da floração, foram acrescentados $22,14 \mathrm{~g}$ de $\mathrm{P}_{2} \mathrm{O}_{5}$ e $27 \mathrm{~g}$ de $\mathrm{K}_{2} \mathrm{O}$. Durante o período de floração, foi realizada a polinização manual das folhas para complementar a polinização pelo agente polinizador natural, as mamangavas (nome científico). A irrigação foi realizada pelo método de aplicação localizada por gotejamento com água salina, oriunda de poço amazonas, de condutividade elétrica $4 \mathrm{dS} \mathrm{m}^{-1}$ ao longo do período de experimento. Forneceram-se, nos primeiros 30 dias, 4 litros, do $31^{\circ}$ ao $90^{\circ}$ dia 12 litros, e a partir da floração, 18 litros planta ${ }^{-1}$, conforme sugestão de Mesquita et al.(2003), para irrigação da cultura com água não salina de condutividade elétrica $0,35 \mathrm{dS} \mathrm{m}^{-1}$. No início da floração, foram colhidas amostras individuais de folhas dos ramos medianos das plantas ( $4^{\mathrm{a}}$ folha a partir do ápice do ramo) de cada parcela, para a avaliação dos teores de macronutrientes das plantas, conforme metodologia descrita por Malavolta et al. (1997). As médias referentes à adubação com NPK foram comparadas entre si, pelo teste "F", a 1 e $5 \%$ de probabilidade, e as doses de biofertilizante foram avaliadas por regressão polinomial.

\section{RESULTADOS E DISCUSSÃO}

Os teores de nitrogênio acumulados na matéria seca foliar das plantas de maracujazeiro sofreram interferência significativa da interação doses de biofertilizante $\times$ adubação com NPK (Figura 1A). Nos tratamentos sem adubação mineral, as doses de biofertilizante ajustaram os teores de $\mathrm{N}$ ao modelo quadrático, em que se obteve o valor máximo de $46,5 \mathrm{~g} \mathrm{~kg}^{-1}$ referente à dose de $44,3 \%$ do insumo orgânico. Nas plantas dos tratamentos com NPK, os valores de $\mathrm{N}$ não se ajustaram a nenhum modelo de regressão polinomial, sendo representados pelo valor médio de $50,81 \mathrm{~g} \mathrm{~kg}^{-1}$ do nutriente. Esses valores são superiores aos $40 \mathrm{~g} \mathrm{~kg}^{-1} \mathrm{de} \mathrm{N}$ verificados por Cruz et al. (2006) em maracujazeiro cultivado em solução nutritiva de condutividade elétrica correspondente a 3,8 $\mathrm{dS} \mathrm{m}^{-1}$. Rodrigues et al. (2009) também verificaram teores adequados de $\mathrm{N}$ em plantas de maracujazeiro-amarelo tratado com biofertilizante e adubação potássica sob irrigação com água não salina. Isso indica que a salinidade da água não influenciou negativamente ao ponto de comprometer o acúmulo de $\mathrm{N}$ pelas plantas.

Embora os valores de $\mathrm{N}$ referentes aos tratamentos com NPK não se tenham ajustado a nenhum modelo de regressão polinomial, as plantas apresentaram maiores teores deste nutriente nas folhas em relação às plantas não tratadas com NPK. Esses resultados expressam as respostas da aplicação mensal de nitrogênio na forma de ureia durante o ciclo da cultura. Por outro lado, mesmo nos tratamentos sem fornecimento de NPK, a aplicação isolada de biofertilizante também resultou em teores de $\mathrm{N}$ adequados às plantas, uma vez que os valores se situam na amplitude de 40 a $50 \mathrm{~g} \mathrm{~kg}^{-1} \mathrm{de} \mathrm{N}$ admi- 
tida como suficiente à cultura por Malavolta et al. (1997) e Oliveira (2002).

As doses de biofertilizantes no solo, sem e com NPK, reduziram e aumentaram, respectivamente, os teores de fósforo na matéria seca foliar das plantas de maracujazeiro-amarelo (Figura 1B). No solo sem NPK os teores foliares de P foram reduzidos de 2,45 para 2,14 $\mathrm{g} \mathrm{kg}^{-1}$ e no solo com NPK aumentaram de 2,53 para $2,78 \mathrm{~g} \mathrm{~kg}^{-1}$. Os valores são inferiores aos $4 \mathrm{~g} \mathrm{~kg}^{-1}$ obtidos por Cruz et al. (2006) em maracujazeiro sob irrigação com solução nutritiva de condutividade elétrica $3,8 \mathrm{dS} \mathrm{m}^{-1}$. Nos tratamentos com NPK, principalmente para as maiores doses do biofertilizante, as plantas acumulam maiores teores de $\mathrm{P}$ na matéria seca em relação aos tratamentos sem adubação mineral. A superioridade é devida à adubação fosfatada com superfosfato triplo, em fundação e em cobertura na fase de florescimento das plantas. No entanto, os teores máximos verificados na matéria seca foliar, mesmo nos tratamentos com NPK, são considerados insuficientes por Malavolta et al. (1997) para o desenvolvimento normal das plantas, pois estão abaixo da faixa entre 4 e $5 \mathrm{~g} \mathrm{~kg}^{-1}$. No entanto, para Oliveira (2002), esses valores são adequados à cultura, uma vez que se situam na faixa entre 2,3 e $2,7 \mathrm{~g} \mathrm{~kg}^{-1} \mathrm{de}$ P. Os resultados também estão coerentes com os de Rodrigues et al. (2009) em maracujazeiro-amarelo irrigado com água não salina, no solo com biofertilizante e adubação mineral, com teor máximo de 3,3 $\mathrm{g} \mathrm{kg}^{-1}$.

Os teores de $\mathrm{K}$ nas plantas tratadas com NPK foram reduzidos de 27,18 para até $20,66 \mathrm{~g} \mathrm{~kg}^{-1}$ com o incremento das doses de biofertilizante. Nos tratamentos sem a adubação mineral, os teores de $\mathrm{K}$ foram significativamente mais baixos e não se ajustaram a nenhum modelo de regressão polinomial, sendo representados pelo valor médio de 19,31 g $\mathrm{kg}^{-1}$ (Figura 2A). Esses resultados são inferiores aos $35 \mathrm{~g} \mathrm{~kg}^{-1}$ de K apresentados por Cruz et al. (2006) em maracujazeiro amarelo em solução nutritiva salina. Mesmo com a redução ocorrida em função do aumento das doses de biofertilizante, os teores de $\mathrm{K}$ no tecido foliar foram superiores nos tratamentos com adubação mineral, em resposta às aplicações de cloreto de potássio em cobertura nas covas, durante o período experimental.

De acordo com Malavolta et al. (1997), os teores de potássio observados na matéria seca das plantas são insuficientes aos exigidos para o suprimento adequado do maracujazeiro-amarelo, que varia entre 35 e $40 \mathrm{~g} \mathrm{~kg}^{-1}$. Por outro lado, estão em acordo com Oliveira (2002), que admite a faixa suficiente de 20 a $30 \mathrm{~g} \mathrm{~kg}^{-1} \mathrm{~K}$, o que enquadraria os valores obtidos nos tratamentos com NPK como suficientes à cultura. $\mathrm{O}$ decréscimo nos teores de $\mathrm{K}$, em função do incremento das doses de biofertilizante nos tratamentos com NPK, pode ser reflexo de competição entre $\mathrm{K}^{+}$e $\mathrm{Mg}^{2+}$ (PRADO et al., 2004; SOUSA et al., 2008) nos sítios de absorção, visto que, de acordo com os dados da Figura 3, os teores de magnésio no tecido foliar estão muito acima dos teores considerados adequados por Malavolta et al. (1997) para a cultura. Por outro lado, é possível verificar que os níveis mais concentrados de biofertilizante apresentam maiores quantidades de sódio (Tabela 1), além de a irrigação com água salina também contribuir com este elemento, o que pode ter provocado o decréscimo na absorção de $\mathrm{K}$ pelas plantas tratadas com NPK, devido à competição entre $\mathrm{Na}^{+}$e $\mathrm{K}^{+}$nos sítios de absorção das membranas celulares (YOSHIDA, 2002; MUNNS; TESTER, 2008).

As doses de biofertilizante aumentaram os teores de Ca da matéria seca das plantas, de 6,35 para 7,55 $\mathrm{g} \mathrm{kg}^{-1}$ no solo sem NPK, e diminuíram de 8,28 para $6,08 \mathrm{~g} \mathrm{~kg}^{-1}$ nas plantas tratadas com NPK (Figura 2B). Esses valores são inferiores aos 9,7 g $\mathrm{kg}^{-1}$ apresentados por Cruz et al. (2006) em maracujazeiro-amarelo sob solução nutritiva com nível salino de 3,8 dS m m $^{-1}$. Embora tenha havido redução dos teores de $\mathrm{Ca}^{2+}$ em função das doses de biofertilizante no solo com NPK, os valores são predominantemente maiores nos respectivos tratamentos em relação aos dos tratamentos sem NPK. Rodrigues et al. (2009) verificaram valores máximos de 6,78 $\mathrm{g} \mathrm{kg}^{-1}$ de cálcio em maracujazeiro tratado com biofertilizante e potássio, e sob irrigação com água não salina.

De acordo com Malavolta et al. (1997) e Oliveira (2002), o maracujazeiro-amarelo encontra-se suficientemente nutrido em $\mathrm{Ca}^{2+}$ quando os teores na matéria seca foliar estiverem entre 15 e $25 \mathrm{~g} \mathrm{~kg}^{-1}$. Dessa forma, os tratamentos não supriram adequadamente as plantas nesse macronutriente, apesar de os teores do elemento no solo estarem em níveis adequados antes da instalação do experimento e de o biofertilizante contribuir com até $1,5 \mathrm{cmol}_{\mathrm{c}} \mathrm{L}^{-1} \mathrm{de}$ cálcio por aplicação, nas doses mais concentradas. Ao considerar que os teores de $\mathrm{Mg}^{2+}$ na matéria seca foliar (Figura 3A) estão muito acima do nível considerado adequado por Malavolta et al. (1997) e Oliveira (2002), possivelmente, esse fenômeno seja resultado da competição entre magnésio e cálcio, causando deficiência de $\mathrm{Ca}^{2+}$ às plantas (MALAVOLTA et al., 1997).

O decréscimo e a consequente deficiência das plantas em cálcio, nos tratamentos com NPK, com o 
incremento das doses de biofertilizante, podem estar relacionados, também, ao incremento de um incremento de $\mathrm{Na}^{+}$no solo, provocado pela água de irrigação. O excesso de sódio inibe a absorção de cálcio pelas plantas (AYERS; WESTCOT, 1999; YOSHIDA, 2002). Além disso, o acréscimo de sulfato e bicarbonato pela água de irrigação e pelas aplicações do biofertilizante deve ter contribuído para a redução da disponibilidade do nutriente no solo.

Os teores de magnésio na matéria seca foliar aumentaram de 4,35 para $8,0 \mathrm{~g} \mathrm{~kg}^{-1}$ nas plantas sem adubação NPK e foram reduzidos de 7,2 para 5,64 $\mathrm{g} \mathrm{kg}^{-1}$ nas plantas tratadas com a adubação mineral (Figura 3A). Cruz et al. (2006) obtiveram valores entre 3 e $4 \mathrm{~g} \mathrm{~kg}^{-1}$ de magnésio em maracujazeiro cultivado em solução nutritiva, moderadamente salina, com condutividade elétrica de $3,8 \mathrm{dS} \mathrm{m}^{-1}$. Mesmo considerando as reduções em função das doses de biofertilizante, nos tratamentos com NPK, os teores do elemento, no tecido foliar das plantas, estão marcadamente acima do admitido como adequado à cultura, com oscilação de 3 a $4 \mathrm{~g} \mathrm{~kg}^{-1}$ (MALAVOLTA et al., 1997). Os altos teores de magnésio refletem a relação direta com os altos teores do macronutriente encontrados no solo, antes da instalação do experimento, e aos incrementos oriundos da irrigação e do fornecimento do biofertilizante.

Os teores de enxofre nas plantas tratadas com biofertilizante e NPK foram reduzidos de 12,82 para até $9,05 \mathrm{~g} \mathrm{~kg}^{-1}$, na dose mínima estimada de $61,6 \%$ do insumo orgânico e não se adequaram a nenhum modelo de regressão no solo sem NPK e foram representados pelo valor médio de $9,39 \mathrm{~g} \mathrm{~kg}^{-1}$ (Figura 3B). Esses valores superam a variação de 4 e 4,6 $\mathrm{g} \mathrm{kg}^{-1}$ apresentada por Cruz et al. (2006) em maracujazeiro-amarelo, desenvolvido sob irrigação, com solução nutritiva salina de $3,8 \mathrm{dS} \mathrm{m}^{-1}$. Entretanto, são inferiores os $16,6 \mathrm{~g} \mathrm{~kg}^{-1}$ de $\mathrm{S}$ determinados por Rodrigues et al. (2009) em maracujazeiro irrigado com água não salina no solo, com biofertilizante $\mathrm{e}$ potássio. Apesar de não se ter fornecido fertilizante mineral contendo enxofre, os resultados expressos pela variação de 12,82 para $9,05 \mathrm{~g} \mathrm{~kg}^{-1}$ e o valor médio de $9,39 \mathrm{~g} \mathrm{~kg}^{-1}$ são expressivamente superiores ao intervalo 3 a $4 \mathrm{~g} \mathrm{~kg}^{-1}$ de $\mathrm{S}$ admitido como suficiente ao maracujazeiro-amarelo (MALAVOLTA et al., 1997). Esses elevados valores nas plantas podem ser devidos à composição do biofertilizante no macronutriente (Tabela 1) e da matéria orgânica oriunda de esterco bovino aplicado na preparação das covas.

TABELA 1- Teores de cátions e ânions dissolvidos, pH e condutividade elétrica (CE) das diferentes amostras e diluições de biofertilizante bovino.

\begin{tabular}{|c|c|c|c|c|c|c|c|c|c|c|}
\hline \multirow{2}{*}{ Biofertilizante } & $\mathrm{Ca}^{2+}$ & $\mathrm{Mg}^{2+}$ & $\mathrm{Na}^{+}$ & $\mathrm{K}^{+}$ & $\mathrm{SO}_{4}^{2-}$ & $\mathrm{CO}_{3}{ }^{2-}$ & $\mathrm{HCO}_{3}^{-}$ & $\mathrm{Cl}^{-}$ & $\mathrm{pH}$ & $\mathrm{CE}$ \\
\hline & \multicolumn{9}{|c|}{ 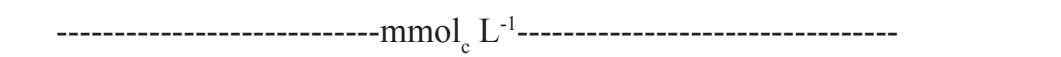 } & $\left(\mathrm{dS} \mathrm{m}^{-1}\right)$ \\
\hline $33,3 \%$ & 9,58 & 10,57 & 8,30 & 8,38 & 5,64 & 0,00 & 2,40 & 23,21 & 5,86 & 0,80 \\
\hline $66,6 \%$ & 11,36 & 13,15 & 9,90 & 9,66 & 10,62 & 0,00 & 4,64 & 30,35 & 6,08 & 4,54 \\
\hline $100 \%$ & 14,59 & 14,72 & 10,67 & 16,23 & 20,26 & 0,00 & 6,79 & 32,49 & 6,10 & 5,15 \\
\hline
\end{tabular}
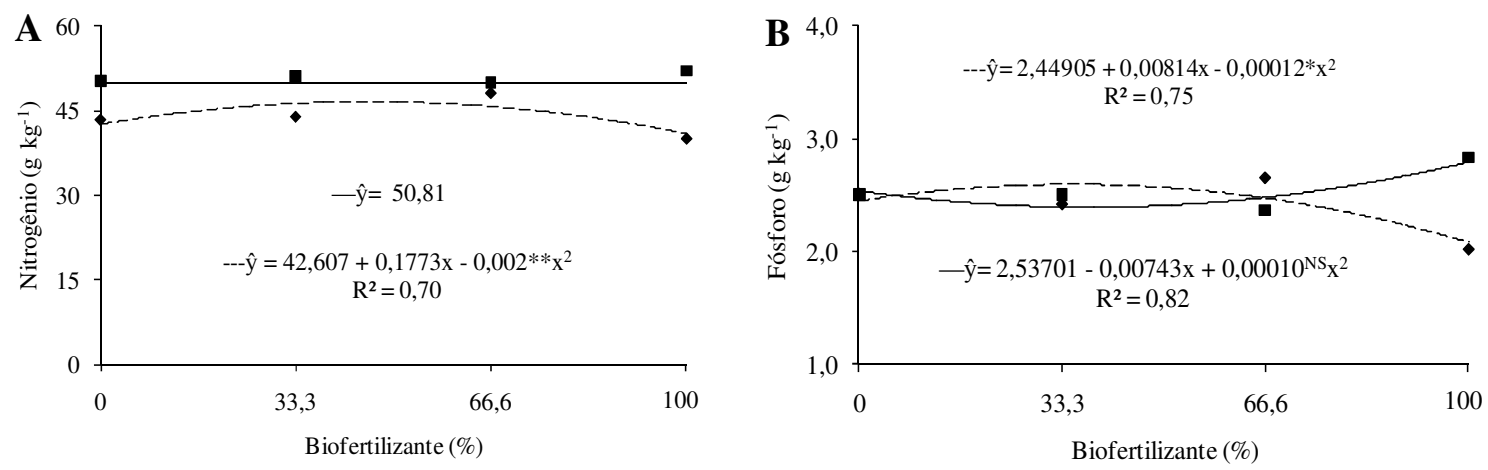

FIGURA 1 - Teores de nitrogênio (A) e fósforo (B) na matéria seca de maracujazeiro-amarelo, em função de doses de biofertilizante comum, no solo sem (---) e com (-) NPK, sob irrigação com água salina. 
A

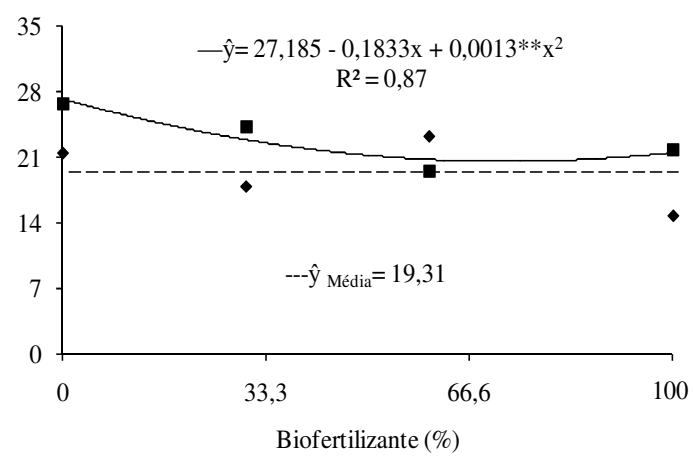

B

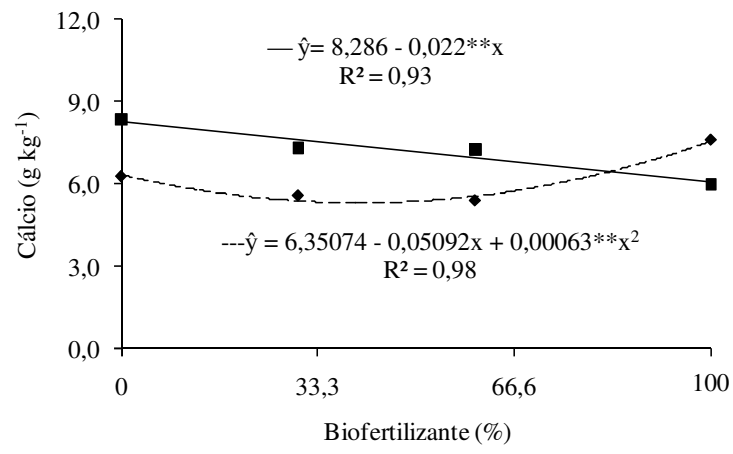

FIGURA 2 - Teores de potássio (A) e cálcio (B) na matéria seca de maracujazeiro-amarelo, em função de doses de biofertilizante comum, no solo sem (---) e com (-) NPK, sob irrigação com água salina.
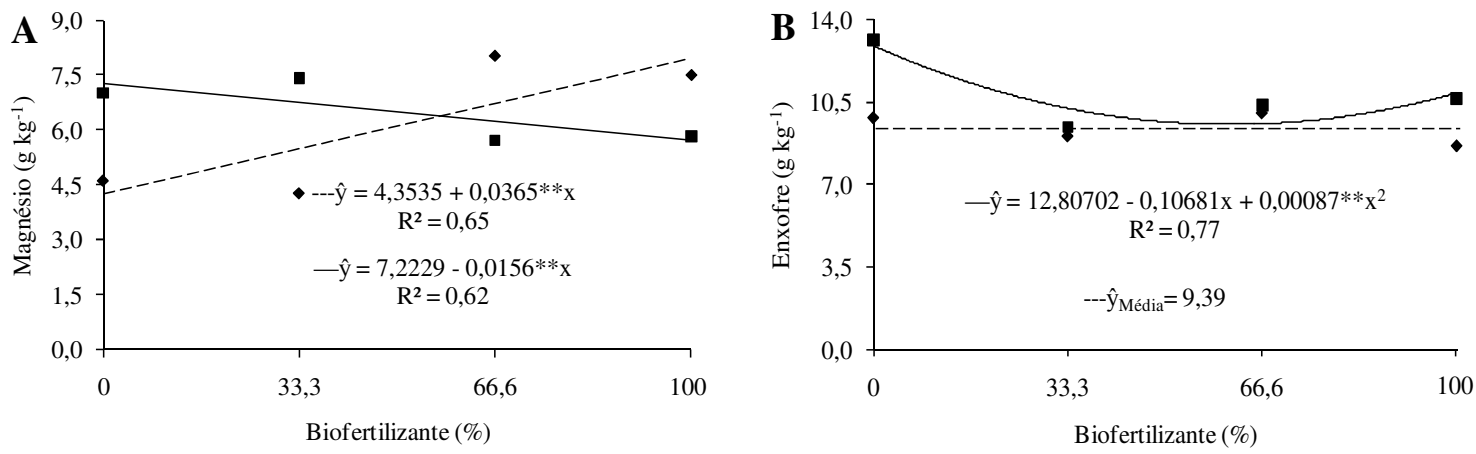

FIGURA 3 - Teores de magnésio (A) e enxofre (B) na matéria seca de maracujazeiro-amarelo, em função de doses de biofertilizante comum, no solo sem (---) e com (-) NPK, sob irrigação com água salina.

\section{CONCLUSÕES}

1. O biofertilizante aplicado ao solo, a cada 60 dias, exceto cálcio, supriu adequadamente as plantas de maracujazeiro-amarelo em macronutrientes, mas com superioridade de valores nos tratamentos com adubação mineral.

2. A salinidade da água de irrigação não influenciou negativamente ao ponto de inibir a absorção dos nutrientes pelas plantas de maracujazeiro.

3. O biofertilizante influencia positivamente na nutrição de maracujazeiro-amarelo irrigado com água salina.

\section{AGRADECIMENTOS}

Ao Dr. Rui Medeiros, pela concessão das plantas para a realização do experimento; ao Conselho Nacional de Desenvolvimento Científico e Tecnológico-CNPq, pela concessão da bolsa de es- tudo, e ao Instituto Nacional de Ciência e Tecnologia em Salinidade - INCTSal, pelo custeamento das despesas durante o período de execução do trabalho.

\section{REFERÊNCIAS}

AYERS, R. S.; WESTCOT, D. W. A qualidade da água na agricultura. 2. ed. Campina Grande: UFPB., 1999. 153 p. (Estudos FAO, Irrigação e drenagem, 29).

BAALOUSHA, M.; HEINO, M. M.; COUSTUMER, B. K. Conformation and size of humic substances: effects of major cation concentration and type, $\mathrm{pH}$, salinity and residence time. Colloids and surfaces. Physicochemical and Engineering Aspects, Amsterdam, v. 222, n.1-2, p. 48-55, 2006. 
CRUZ, J. L.; PELACANI, C. R.; FERREIRA, C. E.; CALDAS, R. C.; ALMEIDA, A. Q.; QUEIROZ, J. R. Influência da salinidade sobre o crescimento, absorção e distribuição de sódio, cloro e macronutrientes em plântulas de maracujazeiro-amarelo. Bragantia, Campinas. v.65, n.2, p.275-284, 2006.

DIAS, N. S.; DUARTE, S. N.; TELES FILHO, J. F.; YOSHINAGA, R. T. Salinização do solo por aplicação de fertilizantes em ambiente protegido. Irriga, Botucatu v. 12, n. 1, p. 135-146, 2007.

DINIZ, A. A. Aplicação de condicionantes orgânicos do solo e nitrogênio na produção e qualidade do maracujazeiro-amarelo. 2009, $98 \mathrm{f}$. Tese (Doutorado) - Universidade Federal da Paraíba, Areia, 2009.

EMBRAPA. Catálago de fruticultura: cultivares da Embrapa 2010. Brasília, 2010. 50 p. (Embrapa Transferência de Tecnologia).

FREIRE, L. O.; CAVALCANTE, L. F.; REBEQUI DIAS, T. J.; NUNES, J. C.; CAVALCANTE, I. H. L. Atributos qualitativos do maracujá-amarelo produzido com água salina, biofertilizante e cobertura morta no solo. Revista Brasileira de Ciências Agrárias, Recife, v.5, n.1, p.102-110, 2010.

HAFLE, O. M.; RAMOS, J. D.; ARAUJO NETO, S. E.; MENDONCA, V. Rentabilidade econômica do cultivo do maracujazeiro-amarelo sob diferentes podas de formação. Revista Brasileira Fruticultura, Jaboticabal, v.32, n.4, p.1082-1088, 2010.

IBGE. Instituto Brasileiro de Geografia e Estatística. Brasília, 2007. Disponível em: <www.sidra. ibge.gov.br/bda/agric>. Acesso em: 15 fev. 2011.

MALAVOLTA, E.; VITTI, G. C.;OLIVEIRA, S. A. Avaliação do estado nutricional das plantas: princípios e aplicações. Piracicaba: POTAFOS, 1997. 201p.

MUNNS, R.; TESTER, M. Mechanisms of salinity tolerance. Plant Biology, Nova York, v.59, p. 651681, 2008.
OLIVEIRA, S. A. Análise foliar. In: SOUZA, D. M. G.; LOBATO, E. (Ed.). Cerrado: correção do solo e adubação. Planaltina-DF: Embrapa Cerrados, 2002. p. 245-256.

PIRES, A. A.; MONNERAT, H. P.; MARCIANO, C. R.; PINHO, L. G. R.; ZAMPIROLLI, P. D.; ROSA, R. C.; MUNIZ, R. A. Efeito da adubação alternativa do maracujazeiro amarelo nas características químicas e físicas do solo. Revista Brasileira de Ciência do Solo, Viçosa, MG, v.32, p. 1997-2005, 2008.

PRADO, R. DE M.; BRAGHIROLLP, L. L.; NATALE, W.; CORREAA, M. C. M.; ALMEIDA, E. V. Aplicação de potássio no estado nutricional e na produção de matéria seca de mudas de maracujazeiro-amarelo. Revista Brasileira de Fruticultura, Jaboticabal, v. 26, n. 2, p. 295-299, 2004.

RESENDE, A. V.; SANZONOWICZ, C.; SENA, M. C.; BRAGA. M. F.; JUNQUEIRA, N. T. V.; FALEIRO, F. G. Manejo do solo, nutrição e adubação do maracujazeiro azedo na região do Cerrado. Planaltina: Embrapa Cerrados, 2008. 33 p. (Documentos, 223)

RODRIGUES, A. C.; CAVALCANTE, L. F.; OLIVEIRA, A. P.; SOUSA, J. T.; MESQUITA, F. O. Produção e nutrição mineral do maracujazeiro-amarelo em solo com biofertilizante supermagro e potássio. Revista Brasileira de Engenharia Agrícola e Ambiental, Campina Grande, v. 13, n.2, p. 117-124, 2009.

SOUSA, F. V.; FOLEGGATTI, M. V.; FRIZZONE, J. A.; DIAS, T. A.; ALBUQUERQUE JÚNIOR. B. S.; BATISTA, E. C. Níveis de irrigação e doses de potássio sobre os teores foliares de nutrientes do maracujazeiro-amarelo. Revista Brasileira de Engenharia Agrícola e Ambiental, Campina Grande, v.12, n.1, p.41-46, 2008.

YOSHIDA, K. Plant biotechnology genetic engineering to enhance plant salt tolerance. Journal Bioscience Bioengineering, Osaka v. 94, n.4, p. 585-590, 2002. 